\title{
ПРОБЛЕМЫ УПРАВЛЕНИЯ ЭНЕРГОСБЕРЕЖЕНИЕМ В ГАЗОТРАНСПОРТНЫХ СТРУКТУРАХ ПАО «ГАЗПРОМ» В КОНТЕКСТЕ ОПТИМИЗАЦИИ ЗАТРАТ ТОПЛИВНО-ЭНЕРГЕТИЧЕСКИХ РЕСУРСОВ ПРИ ТРАНСПОРТИРОВКЕ ГАЗА
}

(c) 2021 Халикова Э.P.

начальник отдела 646/3 Департамента 646 ПАО «Газпром»

соискатель кафедры экономики и управления предприятиями и производственными комплексами Санкт-Петербургский государственный экономический университет, Россия, Санкт-Петербург E-mail:khalikova_er@mail.ru

В статье анализируется система управления энергосбережением в ПАО «Газпром», влияющая на процессы планирования и контроля затрат топливно-энергетических ресурсов на транспортировку газа. Описаны организационная структура, методическая база, особенности контроля, характеризующие результативность созданной системы. Выявлены проблемы, влияющие на эффективность управления, предложены методы их решения.

Ключевые слова: энергосбережение, топливно-энергетические ресурсы, транспортировка газа, природный газ.

В связи со значимостью задачи экономии энергоресурсов, занимающих в структуре затрат газотранспортной системы (ГТС) второе место после арендной платы газотранспортных дочерних обществ (ГТДО) за пользование основными средствами головной компании ПАО «Газпром», актуальность рассмотрения вопросов энергоемкости и энергоэффективности ГТС не вызывает сомнений. На необходимость продолжения исследований в этом направлении также указывается в Энергетической стратегии России на период до 2030 года: «Главной проблемой в сфере снижения энергоемкости экономики является значительный нереализованный потенциал организационного и технологического энергосбережения, составляющий до $40 \%$ общего объема внутреннего энергопотребления» [3]. С учетом того, что процесс транспортировки природного газа по магистральным газопроводам, на который приходится $75,1 \%$ суммарного энергопотребления, является наиболее энергоемким видом деятельности ПАО «Газпром» становится очевидно, что решение проблем энергосбережения и энергоэффективности ГТС неразрывно связано с задачей оптимизация затрат топливно-энергетических ресурсов (ТЭР) и режимов транспортировки газа.

В целях эффективного решения задачи энергосбережения в ПАО «Газпром» сформирована система, охватывающая все ключевые этапы управления процессом: создана структура руководящих органов, нормативно-методическая база, методика корпоративного учета показателей эффективности расхода ТЭР, разработан и апробирован комплекс энергетических обследований производственно-технологических объектов Общества, внедрен механизм контроля за эффективностью расхода газа на собственные технологические нужды (СТН) ГТДО.

Структура управления энергосбережением, нацеленная на реализацию мер максимизации экономии энергоресурсов, осуществляет сквозную координацию вопросов энергосбережения от холдинговой компании до дочерних обществ (рис. 1).

Помимо руководящих органов Структура управления энергосбережением и энергоэффективностью ГТС, связана с разработкой нормативно-методической базы, формированием системы учета показателей эффективности расхода ТЭР, внедрением методик энергетических обследований объектов ГТС, системы контроля эффективности расхода газа на собственные технологические нужды ДО и методов стимулирования реализации оптимального режима транспорта газа (рис. 2) [2, С.10].

В соответствии с системой управления энергоэффективностью ГТС в ПАО «Газпром» постоянно формируется и совершенствуется нормативно-методическая база энергосбережения, охватывающая вопросы разработки внедрения и контроля программ энергосбережения, нормирования расходов ТЭР оценки показателей эффективности расходования ТЭР, в том 


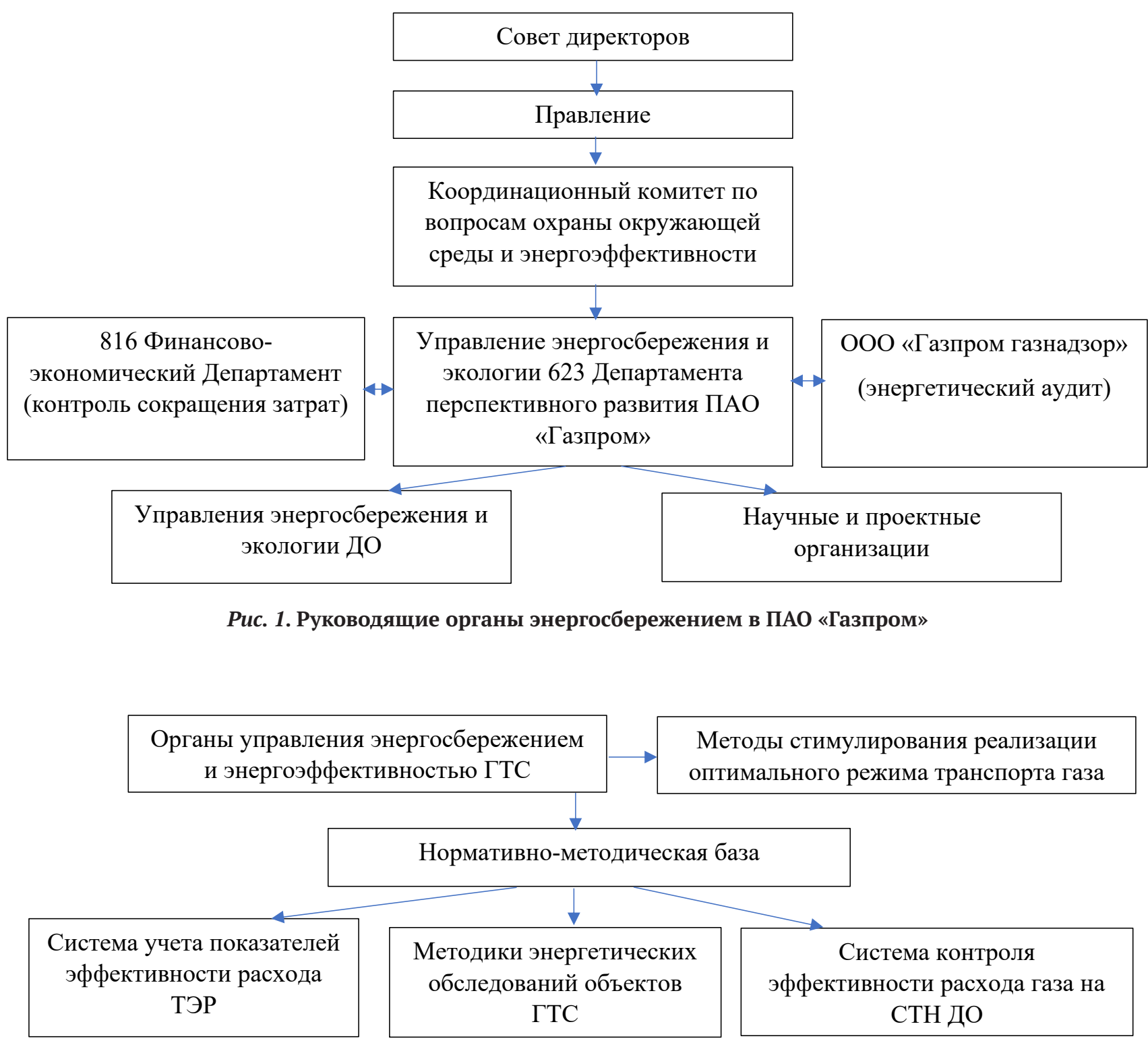

Puc. 2. Организационная структура управления энергосбережением и энергоэффективностью ГТС

числе экономической эффективности энергосбережения, энергетических обследований объектов ГТС, требований к оборудованию ГТС [2, C.18].

Основными документами, регламентирующими функционирование системы управления энергоэффективностью и энергосбережением ГТС являются:

- Политика ПАО «Газпром» в области энергоэффективности и энергосбережения;

- Трехлетние программы энергосбережения, разрабатываемые и реализуемые ГТДО на основе Политики;

- Концепция энергосбережения и повышения энергетической эффективности ОАО
«Газпром» на период 2011-2020 гг. (далее Концепция энергосбережения);

- ГОСТ: Р 53905-2010 Энергосбережение. Термины и определения; 31607-2012 Межгосударственный стандарт. Энергосбережение. Нормативно-методическое обеспечение; ГОСТ Р 51541-99. Энергосбережение Энергетическая эффективность. Состав показателей. Общие положения;

- СТО Газпром: 2-3.5-113-2007 Методика оценки энергоэффективности газотранспортных объектов и систем, 2.1.20-122-2007 Методика проведения энергоаудита компрессорной станции, компрессорных цехов с газотурбинными и электроприводными газоперекачиваю- 
щими агрегатами, 2-1.20-114-2007 Методика энергоаудита газотранспортных систем и др.

Концепцией энергосбережения регламентирован порядок осуществления надзора за эффективным использованием ТЭР, энергоэффективностью технологических процессов и оборудования ГТС, согласно которому реализуются:

- постоянный контроль: определение и анализ показателей энергоэффективности технологических процессов и оборудования; контроль фактической эффективности реализованных энергосберегающих мероприятий;

- периодический контроль на основе технического инструментального обследования: учет суммарного и удельных расходов ТЭР; определение и анализ показателей энергоэффективности технологических процессов и оборудования; определение потенциала энергосбережения обследуемого объекта; определение степени оснащенности обследуемого объекта средствами измерения расхода ТЭР; контроль состояния энергетических паспортов технологических объектов ОАО «Газпром» [2, С. 16-17].

Основными функциями органов контроля являются разработка рекомендаций по улучшению показателей использования газа, согласование предложений ДО в Программу энергосбережения, а также проверки организаций ПАО «Газпром» на предмет:

- соблюдения установленных норм и объе- мов потребления газа по видам их деятельности; - эффективности использования газа на $\mathrm{CTH}$;

- выполнения программ энергосбережения;

- выполнения рекомендаций по устранению недостатков при использовании газа на $\mathrm{CTH}$.

Учитывая тот факт, что система управления энергосбережением позволяет ежегодно достичь я экономии удельного расхода ТЭР на транспорт газа не ниже плановых нормативов, тем не менее нельзя не признать наличие ряда проблем управления этим процессом.

Сложившаяся в холдинге система управления затратами ТЭР на транспорт газа характеризуется 2-мя важными особенностями, снижающими ее эффективность по причине рассогласованности целеполагания: с одной стороны, безусловным приоритетом в работе ГТС является обеспечение своевременных поставок газа потребителям согласно договорным обязательствам; с другой стороны, важнейшая задача, определяемая Политикой ПАО «Газпром» в области энергоэффективности и энергосбережения, - ежегодное сокращение удельного расхода газа на товаротранспортную работу (ТТР). Учитывая приоритет договорных обязательств, технологами газотранспортных обществ с учетом ряда объективных обстоятельств (техническое состояние оборудования ГТС, своевременный ремонт участков линейной части МГ и ГПА и т.д.)

\section{OOO «Газнадзор»}

Зоны ответственности

\begin{tabular}{|l|l|}
\hline \multicolumn{2}{|c|}{ Зоны ответственности } \\
\hline $\begin{array}{l}\text { Контроль за эффективным использованием } \\
\text { газа, расходуемого на СТН основного и } \\
\text { вспомогательного производств при добыче } \\
\text { транспортировке, подземном хранении, } \\
\text { переработке и распределении ресурсов газа. }\end{array}$ & $\begin{array}{l}\text { Контроль за реализации требований ФЗ о } \\
\text { проведении обязательных энергетических } \\
\text { обследований и энергетических аудитов в } \\
\text { целях оценки эффективности использования } \\
\text { топливно-энергетических ресурсов }\end{array}$ \\
\hline
\end{tabular}

\begin{tabular}{|c|c|}
\hline \multicolumn{2}{|c|}{ Объекты контроля } \\
\hline$\Downarrow$ & $\mathbb{\Downarrow}$ \\
\hline $\begin{array}{l}\text { ДО, потребители газа в части } \\
\text { соблюдения технико- } \\
\text { эксплуатационных условий договоров } \\
\text { поставки газа }\end{array}$ & $\begin{array}{l}\text { ДО, организации ОАО "Газпром" с } \\
\text { потреблением энергетических } \\
\text { ресурсов более } 6 \text { тыс. т условного } \\
\text { топлива в год }\end{array}$ \\
\hline
\end{tabular}


не всегда обеспечивается оптимальный энергоэффективный режим транспортировки газа.

Другая немаловажная проблема управления энергосбережением, существенно влияющая на затраты ТЭР, - отсутствие единого системного подхода к использованию ГТДО оптимальных режимов транспорта. Данная проблема во многом связана как с постоянно меняющимися внешними условиями поставок газа, снижающими эффективность планирования затрат ТЭР, так и с внутренними факторами: несовершенством программного обеспечения, отсутствием критерия оптимальности режимов транспорта, обоснованного физическими законами течения газа, неточностью измерений расхода ТЭР в компрессорных цехах, используемых при планировании режимов.

Третья проблема управления затратами ТЭР - отсутствие корректного измерения и оценки результата от их экономии в стоимостном эквиваленте и по отношению к объему транспортируемого газа (рис. 4).

Так, внедрению в ГТДО единого системного подхода к использованию оптимальных режимов транспорта газа, в частности, препятствуют следующие факторы:

1. Изменение объемов поставок газа, необходимость проведения ремонтов, ТО ГТС, требующие постоянных корректировок затрат ТЭР;

2. Несовершенство программного обеспе- чения (ПО), используемого при планировании режимов;

3. Отсутствие обоснованного критерия оптимальности режима транспорта газа;

4. Неточность измерений затрат ТЭР в компрессорных цехах.

Если рассмотреть более подробно, то можно сказать:

- систематическая необходимость технического обслуживания оборудования ГТС, текущих и капитальных ремонтов трубопроводов, изменение объемов поставок газа вследствие постоянного процесса контрактаций негативно влияют на точность прогнозирования загрузки системы. Оперативный ежемесячный план-фактный анализ затрат топливного газа приводит к значительным ежеквартальным корректировкам, что делает долгосрочное планирование малоэффективным и снижает действенность контроля за выполнением плановых показателей.

- другой важнейшей проблемой планирования затрат ТЭР являются недостатки методики определения оптимального режима транспорта газа. В частности, это несовершенство используемых при планировании режимов программно-вычислительных комплексов, не предусматривающих определение оптимальной конфигурации сети, в т.ч. включения ниток газопровода для транспортировки газа «на про-

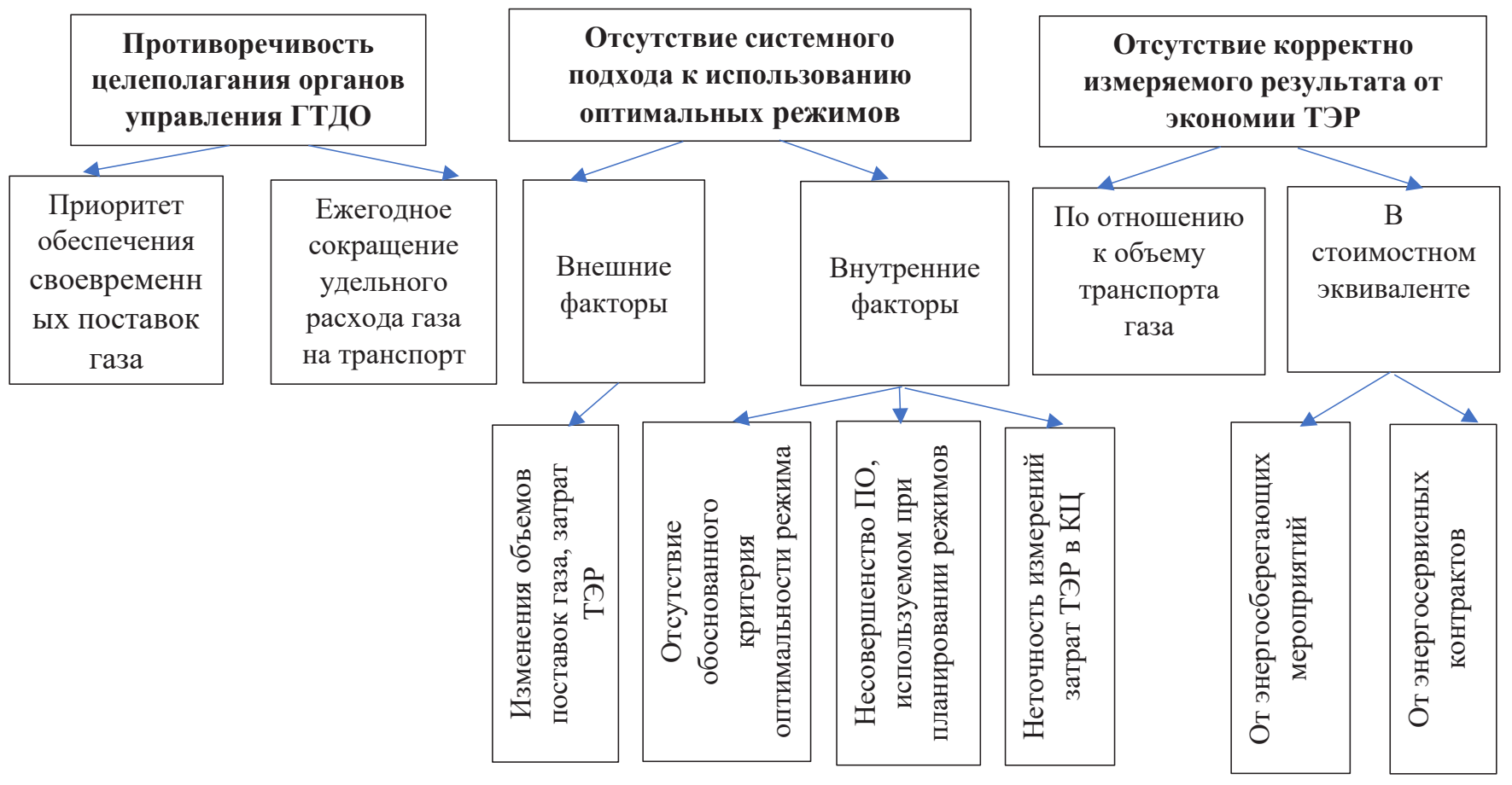

Puc. 4. Проблемы управления затратами ТЭР на транспорт газа 
ход». Наличие множественности вариантов загрузки цехов, перестройки маршрутов транспортировки ставит оптимизацию затрат ТЭР в прямую зависимость от опыта и квалификации диспетчеров.

Для поддержки принятия диспетчерских решений в режиме реального времени в ДС ГТДО установлено ПО, моделирующее процесс транспорта газа по ГТС ГТДО. В ПАО «Газпром» используется несколько типов ПО («Астра», «Волна», «Веста», GOFO), но ни одно ПО не является так называемым цифровым двойником, а служит лишь неким аналогом ГТС с нетарированной погрешностью.

Отчасти по этой причине, а отчасти потому, что при работе реального участка ГТС могут варьироваться порядка 100 параметров, оптимизация режима транспорта газа с целью минимизации затрат ТЭР при помощи имеющихся ПО в настоящее время практически невозможна.

- как следует из физики процесса транспортировки газа, на величину затрат ТЭР существенно влияют шероховатость труб газопровода и характеристики оборудования компрессорных станций. На сегодня учет данных факторов при определении оптимального режима транспорта газа и минимальных затрат топливного газа нуждается в системной доработке.

При сдаче проекта проектными организациями осуществляется прогноз потребления ТЭР на основании расчета с учетом паспортных характеристик установленного оборудования труб линейной части, а также внешних условий: температуры воздуха, грунта и объема транспорта газа (входит в проектное задание). После строительства при сдаче объекта службам эксплуатации не проводится паспортизация МГ или участка ГТС в плане потребления ТЭР на соответствие фактических данных проектным и как основа будущего планирования потребления ТЭР от заданий на транспорт газа. - СТО Газпром 2-1.20-114-2007 Методика энергоаудита газотранспортной системы, позволяющая оценить состояние оборудования не только КС, но и ЛЧМГ, фактически не применяется. В настоящее время отменено и проведение периодического энергоаудита. Как следствие, у разработчиков СТО отсутствует обратная связь с эксплуатирующими ГТДо, не происходит необходимая корректировка нормативной документации, возможная лишь в ходе ее апробации и опытно-экспериментальной работы.
Как следствие, на текущий момент в процессе планирования затрат ТЭР на транспорт газа и при оценке энергоэффективности работы ГТДО не всегда учитывается техническое состояние оборудования, а если учитывается, то результаты его диагностики вносятся в ПВК в режиме ручной корректировки.

- методика расчета норм удельного расхода топливного газа и электроэнергии, закрепленная в СТО Газпром 3.3-2-044-2016, учитывает техническую оснащенность и характеристики оборудования КС: количество агрегатов, их производительность, КПД [12, С. 12-16], влияющие на показатели энергоэффективности ГТДО, достижение которых обеспечивается при расчете оптимального режима транспорта газа на каждой КС. При этом СТО Газпром 2-3.5-113-2007 предусматривает погрешности результатов измерений или расчетов параметров энергоэффективности обследуемого оборудования в пределах от 5,3 до 10,1\%, вызванные инструментальными или методическими неточностями. Ситуация осложняется тем, что оптимальные затраты ТЭР на транспорт газа рассчитываются на основании проектов МГ, выполненных проектными институтами ПАО «Газпром», выбора установленного оборудования и, в соответствии с ним, проектного номинального режима транспорта газа. Но в процессе эксплуатации совпадение проектного и фактического режимов наблюдается крайне редко, техническая документация не содержит полного объема информации по параметрам оборудования на неноминальных режимах, кроме того, со временем в процессе эксплуатации оборудование заменяется на более современное, что значительно снижает ценность расчетных показателей из-за изначально заложенных в них недостоверных технических характеристик. Это должно учитываться в модели оптимизационного программно-вычислительного комплекса.

Кроме того, проблема корректности измерений затрат ТЭР, влияющая на оценку энергоэффективности работы ГТДО, актуализируется в связи со следующими особенностями соответствующих бизнес-процессов.

С одной стороны, измерение расхода топливного газа и электроэнергии на компримирование газа в компрессорном цехе производится с достаточно высокой точностью посредством использования измерительных диафрагм и датчиков расхода топливного газа и других инструментов. С другой стороны, измерение рас- 
ходов ТЭР не всегда предполагает оценку затрат только на компримирование - в них включены также расходы ТЭР на другие виды собственных технологических нужд (СТН).

В подавляющем большинстве КЦ расходы ТЭР измеряются в целом на цех, в котором установлено несколько ГПА и АВО. Это приводит к тому, что без дополнительного анализа при помощи специализированных программ (которых в КЦ нет) или без проведения дополнительных специальных измерений в процессе энергообследования невозможно точно определить характеристики отдельных ГПА и АВО.

С учетом того, что количество установленных ГПА и АВО может существенно превышать количество работающих в текущем режиме, точность прогноза затрат ТЭР при работе КЦ достаточно невысокая. Как результат при прогнозировании потребления ТЭР диспетчерская служба (ДС) вынуждена опираться на паспортные характеристики оборудования, занижая коэффициент его технического состояния (.

Измерение объема транспорта газа через газотранспортное дочернее общество (ГТДО) производится на газоизмерительных станциях (ГИС), обладающих достаточно высокой точностью. При этом ГИС установлены на границах не всех ГТДО.

Поскольку потребление газа на СТН составляет не более нескольких процентов от объема транспорта газа, то проверить данные о потреблении газа ГТДО с помощью ГИС практически невозможно: погрешность измерений ГИС является слишком большой для точного измерения потребления газа на СТН. Этот факт является причиной еще одной проблемы разбаланса газовых потоков (в данной работе эта проблема не исследуется).

Невозможность в процессе транспорта газа по магистральному газопроводу (МГ) подтвердить с достаточной точностью фактическое потребление газа на СТН на интегральном уровне путем вычисления разности объемов входящего и исходящего потоков газа в газотранспортной системе (ГТС) существенно снижает вероятность доказать эффективность проведения различных, в том числе энергосберегающих мероприятий. Этот факт приводит к необходимости проводить специальные эксперименты по каждому энергосберегающему мероприятию отдельно, предварять эти эксперименты теоретическим анализом и разработкой валидной методики проведения эксперимента.

Совокупность вышеприведенных проблем снижает эффективность принятия обоснованных решений в области управления газотранспортными потоками с целью снижения энергопотребления ТЭР, а также не позволяет объективно оценивать правильность и точность принятых решений.

Недостатки системного подхода к минимизации затрат ТЭР на транспорт газа высвечивают еще одну проблему: отсутствие корректно измеряемого результата от экономии ТЭР. Частично это связано с тем фактом, что потребление ТЭР ГТДО составляет несколько процентов от объема транспортируемого газа, что не дает ощутимого эффекта в стоимостном выражении с учетом приоритета сроков доставки газа потребителям.

Основной причиной обозначенной проблемы является отсутствие методики комплексной оценки экономического эффекта от энергосберегающих мероприятий. Как следствие отсутствует ясность в понимании их целей: минимизацию чего именно необходимо обеспечить? Возможные варианты:

- минимизировать общее потребление ТЭР в т.у.т.;

- минимизировать затраты на ТЭР в рублях.

В последнем случае возникают вопросы: 1) каково должно быть оптимальное соотношение электроэнергии и топливного газа в структуре затрат ТЭР на транспорт? 2) по какой цене учитывать сэкономленный природный газ? Возможные варианты: цена НДПИ на газ; цена газа на СТН для ГТДО; цена газа для российских потребителей; цена газа на экспорт; некая средневзвешенная цена на газ.

Данные вопросы является основными для экономического обоснования оптимальных режимов транспорта газа.

Между тем, как констатировалось выше, оптимизация режима транспорта газа, с учетом энергоемкости процесса, «веса» топливного газа в структуре затрат ГТС, является основным средством достижения энергосберегающего эффекта. Наиболее перспективными решениями данной проблемы, на наш взгляд, должны явиться:

1) паспортизация действующих и вводимых МГ как единого элемента ГТС, под которой подразумевается экспериментальное определение реальной зависимости потребления ТЭР МГ от объема транспорта газа при пуске газопровода в эксплуатацию; 
2) выработка и обоснование единого критерия оптимальности затрат ТЭР на транспорт газа, разработка понятной и малозатратной методики планирования затрат ТЭР на транспорт газа;

3) опытно-экспериментальная работа, связанная с апробацией и внедрением методики определения оптимальных режимов транспорта газа для каждого ГТДО;

4) изменение нормативной документации, связанной с планированием ТЭР на транспорт газа;
5) текущий контроль за режимами транспорта газа по МГ и фактическим потреблением ТЭР;

6) экспресс-анализ и быстрое устранение возникающих «узких» мест в процессе транспорта газа;

7) создание системы обратной связи между эксплуатирующими ГТДО, ведомствами по планированию затрат ТЭР и разработчиками нормативной документации для своевременной и обоснованной корректировки директивных показателей.

\section{Библиографический список}

1. Концепция энергосбережения и повышения энергетической эффективности ОАО «Газпром» на период 2011-2020 гг. (утв. приказом ОАО «Газпром» от 28.12.2010 № 364).

2. СТО Газпром 4-2005 Положение о порядке осуществления ОАО «Газпром» контроля за эффективным использованием газа. - М: ООО «Газнадзор», дата введения: 01.06.2005.

3. Энергетическая стратегия России [Текст]: за период до 2030 года: утверждение решением Правительства Российской Федерации от 13 ноября 2009 г. № 1715-Р / М-во энергетики Российской Федерации. - Москва: Ин-т стратегической энергии, 2010. - 183 с.

4. Политика ПАО «Газпром» в области энергоэффективности и энергосбережения. 